\title{
Point and Space Groups for Hydroxyapatite by Computer Simulation of CBED Electron Diffraction Patterns.
}

\author{
Elson Sánchez-Pastenes ${ }^{*}$, José Reyes-Gasga ** \\ *elson@fisica.unam.mx, ${ }^{* *}$ jreyes@fisica.unam.mx
}

Instituto de Física. Universidad Nacional Autonoma de México, Apdo. Postal 20-364

Ciudad Universitaria 01000, México, D.F. México.

Hydroxyapatite is the main component of teeths and bones [1] its study is of great importance for its application in the field of biomaterials although its structure has not been totally characterized. The synthetic or pure hydroxyapatite has the chemical formula $\mathrm{Ca}_{4}(1) \mathrm{Ca}_{6}(2)\left(\mathrm{PO}_{4}\right)_{6}(\mathrm{OH})_{2}$ [2] with hexagonal unit cell and parameters $\mathrm{a}=0.942 \mathrm{~nm}, \mathrm{c}=0.688 \mathrm{~nm}$, but it is known that in natural form it is not totally pure, since it allows with easiness the accommodation of atoms of impurity in its unitary cell, for example, the $\mathrm{OH}$ groups occupy disordered positions above or below the triangles formed by the $\mathrm{Ca}(2)$ atoms. The disorder of the $\mathrm{OH}$ groups gives rise to "macroscopic" space group $\mathrm{P}_{3} / \mathrm{m}$, because the $\mathrm{OH}$ can removed of their positions with a very small energy what would cause a structural disorder which produces the forbidden reflections along $\mathrm{c}^{*}$ axis [3], an this disorder could been producer a chemical disorder along the column of the hydroxyls, which destroy the axis screw. The sites $\mathrm{Ca}(1)$ and $\mathrm{Ca}(2)$ can removed with $\mathrm{Na}$, $\mathrm{Mg}, \mathrm{K}, \mathrm{Al}$, etc., [2] these ions cause expansion in both the a and $\mathrm{c}$ axis dimensions.

In figures $1 \mathrm{a}$ and $1 \mathrm{~b}$ the CBED pattern is shown in ZOLZ along the [0001] direction, where the symmetry shown is 6 , where the dynamic lines and the absence of the forbidden reflections are observed. In figures $1 \mathrm{c}$ and $1 \mathrm{~d}$ the Kikuchi lines in FOLZ and ZOLZ are shown. Here we observe the importance that the computer simulation of CBED pattern has, because the information they give us and the fit they show in these images are quite good.

Therefore, the determination of the point and space group symmetry in crystals is a previous and indispensable step to begin the determination of the crystal structure for natural hydroxyapatite. Any error makes impossible the structural solution, in particular for atoms of impurity and substitutions.

In the present work we present and comment the main crystallography characteristics of computer calculated CBED patterns for synthetic HAP [4] to use them as starting point for the theoretical and experimental characterization of natural HAP

\section{References}

1. Le Geros RZ, Calcium Phosphates in Oral Biology and Medicine, Howard M. Myers, Sn. Francisco Cal. (1991)

2.-E.F. Brés et al. Acta Cryst. (1993). B49, 56-62.

3. Brés E.F. J. of Microscopy 170 (1993b) 147.

4.- E. Pastenes, J. Reyes-Gasga. RLMM Vol. 21, No.2, 2001, 69-73.

The authors thank the technical support of Ing. Manuel Aguilar Franco, C. D. Guadalupe Rodríguez, Sr. Pedro Mexía H, Sr. Carlos Flores M. Ing. Samuel Tehuacanero, Ing. Cristina Zorrilla, M. en C. Jacqueline Cañetas.

This work was sponsored by DGAPA-UNAM (Project IN-104902).. 

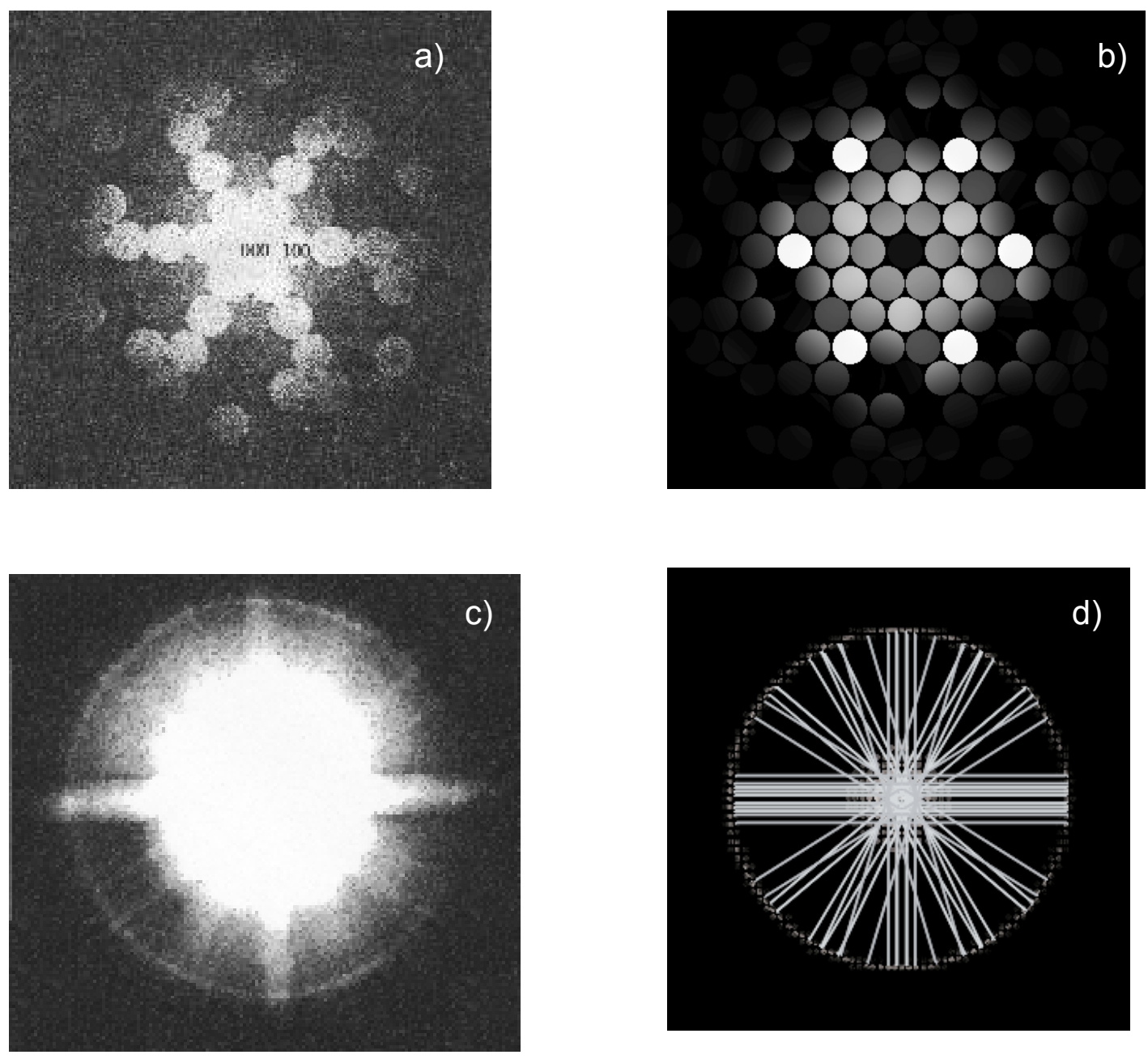

Fig 1. Experimental and calculated CBED patterns for pure HAP. a) and b) CBED patterns in ZOLZ along [0001] direction, c) and d) Kikuchi lines pattern with ZOLZ and FOLZ along $[1 \overline{1} 20]$ direction.

Note the similarity along these patterns. 